\title{
A SOFTWARE TOOL OF TECHNICAL AND FINANCIAL-ECONOMIC ANALYSIS FOR ACQUISTION OF BROADBAND RADIO PPDR NETWORKS
}

Henryk Gierszal, Ph.D.

Adam Mickiewicz University

Umultowska 85, Poznań, Poland

e-mail: gierszal@amu.edu.pl

Karina Pawlina, M.Sc.

Piotr Tyczka, Ph.D.

Krzysztof Romanowski, M.Sc.

ITTI Sp. z o.o.

Rubież 46, Poznań, Poland

Maria Urbańska, Ph.D.

Poznań University of Life Sciences

Wojska Polskiego 71C, Poznań, Poland

Received 3 November 2015, Accepted 27 June 2016

\begin{abstract}
In this paper, we present a software tool that allows preparing econometric analyses aiming at selection of optimal business models for acquisition of broadband mobile networks by PPDR organizations. Such agencies often and often need broadband services to improve operational activities in order to increase the safety, security, and their effectiveness in day-to-day and crisis situations. Upgrade or migration to broadband networks needs careful decisions so as to find a justified trade-off between CAPEX and OPEX. The network evolution can be based on different business models but any approach cannot degrade the reliability, security, and resilience required by PSC.
\end{abstract}

Keywords: PPDR systems, business models, financial-economic analyses, radio systems

JEL classification: $\mathrm{O} 33$ 


\section{Introduction}

Public Protection and Disaster Relief (PPDR) is an important sector in every country because it takes care of the safety and security in many dimensions of the society and economy, including citizens and infrastructures. PPDR organizations need Public Safety Communication (PSC) networks. Such networks have to be secure and reliable, and bear different services in routine day-to-day activities, planned major events as well as major incidents or even disasters.

For several years a new requirement has been manifested by PPDR agencies, i.e. the need of broadband transmission for their operational activities, e.g. to use video streaming services. This demand results from the impressive evolution of mobile technologies, that nowadays allow reaching the throughput of even over hundred Mbits per second using 4G LTE standard. Thus, such an evolution of PPDR networks seems obvious, but decision makers pose a question about its costs. In order to reduce them, many business models have been being analyzed to reach this goal while keeping PPDR requirements as strict as possible even though both criteria are contradictory and a trade-off is needed.

To facilitate those analyses, a software tool was developed by the authors and tested on the basis of several business case studies, that were investigated in Poland and other European countries. This tool allows preparing and evaluating different business models of communications network acquisition, including investment and operational stages. Comparisons can be done in forms of tables as well as charts for easier interpretations and drawing conclusions from the results. The tool is based on two software components: (1) spreadsheet workbook based on Microsoft Excel, where many scripts were written in Visual Basic, and (2) open-source $R$ framework.

The organization of the paper is the following. The software tool developed for business analyses is described in Section 1. Sections 2 to 6 demonstrate a few case studies elaborated with this tool. The first example in Section 2 compares the results of a financial and economic analysis of several business models that can be used to acquire a broadband PPDR network. In Section 3, the acquisition of narrow- or wideband trunking networks in several European countries is evaluated. A case that aimed at selecting one of two business models where a nationwide radio dispatching network is based on one of two technologies is presented in Section 4. The last example in Section 5 shows how one can itemize different types of expenditures borne to build a narrowband radio dispatching network for the crisis management in a voivodeship in Poland. Another case study in Section 6 concerns a network planning where radio transmission is affected by greater attenuation resulted from clutter types. Finally, conclusions are presented in Section Conclusions. 


\section{Business-oriented tool}

For technical and financial-economic analyses, a software tool based on a spreadsheet workbook has been developed to support end-users, first responders, and decision makers in a challenging process of acquisition of broadband PPDR networks. The acquisition can be done by purchasing and installing the infrastructure equipment, or by leasing the communication services from a service provider or a network operator. In order to have a holistic view on this process, the acquisition comprises also the stage of operation and maintenance of the network. The tool can analyze business models of the acquisition in a multi-domain space in order to be able to search a trade-off between end-user's requirements and available funds. It allows providing a series of efficiency indices that can be used to compare different business models and scenarios of deploying a PPDR network taking into account provided services and functions, as well as capital and operating expenditures. The analyses that can be done with this tool are performed in the following dimensions:

- technical - by identification of functionalities and the size of communication network(s),

- financial - through a financial analysis, including Capital Expenditures (CAPEX) and Operational Expenditures (OPEX),

- economic - by estimation of different economic benefits that an end-user can gain due to acquisition of a new network,

- organizational - through the allocation of investments and operating/managing/ maintaining costs associated with the network into entities of four roles: owner, operator, virtual operator, or user.

The tool allows end-users tuning different opposing dimensions in order to find an optimum that satisfies requirements at accepted level of tolerance or uncertainty. One can reduce the preferable size of the network to decrease the overall cost of the acquisition, or, conversely, increase the required Quality of Service (QoS) agreed in the Service Level Agreement (SLA) if extra funds can be allocated. The SLA is expressed by e.g. coverage area or redundancy of deployed base stations. Better SLA conditions affect CAPEX when the network is built, or OPEX (monthly fee) when the acquisition is based on leased communication services.

To define a scenario for the business model in the tool, the following items have to be defined:

1. functionalities of resulting PPDR network that is to be acquired; they are grouped into the following categories: voice, narrowband data transmission (up to $384 \mathrm{kbps}$ ), 
broadband data transmission (above $384 \mathrm{kbps}$ ), video (data transmission with tighter latency), transversal services, and challenging services;

2. technologies for sub-networks that are parts of the network; 9 technologies are predefined;

3. financing models of the acquisition (built, leased) and operation (own, outsourcing);

4. size of the sub-networks (the number of switches, base stations, terminals, network operation centres, etc.);

5. amount of economic benefits needed to calculate economic efficiency.

They are shown in Figure 1. An end-user selects also the way in which the analysis is done. It can be a bottom-up or top-down approach. In the latter, the value of one of the parameters (i.e., the number of terminals, the number of base stations, or the number of years of investment) is tried to be fitted to the assumed project budget.

The effect of the multi-domain analysis is a set of tables and charts that are presented in the following groups (Grazia et al., 2015; Gierszal et al., 2012):

- financial analysis (e.g. Total Cost of Ownership (TCO), CAPEX and OPEX, Net Present Value (NPV), Internal Rate of Return (IRR)),

- economic analysis (Economic NPV (ENPV), Economic IRR (EIRR), Benefit-Cost ratio (B/C), Dynamic Generation Cost (DGC)),

- organizational analysis that shows relations between the parties involved in a network project,

- Strength, Weakness, Opportunity and Threat (SWOT) analysis.

DGC is equal to a price which ensures a balance between discounted effects and discounted expenditures:

$$
D G C=\frac{\sum_{t=0}^{n} \frac{K I_{t}+K E_{t}}{(1+r)^{t}}}{\sum_{t=0}^{n} \frac{E E_{t}}{(1+r)^{t}}}
$$

where $K I_{t}$ is investment expenditures in year $t ; K E_{t}$ - operation, management, and maintenance costs in year $t ; E E_{t}$ - a measure of the resulting effects in year $t ; r$ - a discount rate; and $n-$ a lifetime of the project.

DGC is considered as a good measure of cost-effectiveness because it takes into account the expenditures and quantitative data for the whole period of the project duration, and it is expressed in a fee per service (Raczka, 2003). This index manifests the amount of expenditures allocated to the infrastructure that is borne in order to obtain a unit of targeted effect(s). DGC is a very good approximation of a long run average cost. If the value is great, a decision maker 
can either accept high costs (because there are no alternatives or important resulting (economic) effects exist) or reject the project of the planned network.

Defintion of scenario

Analysis
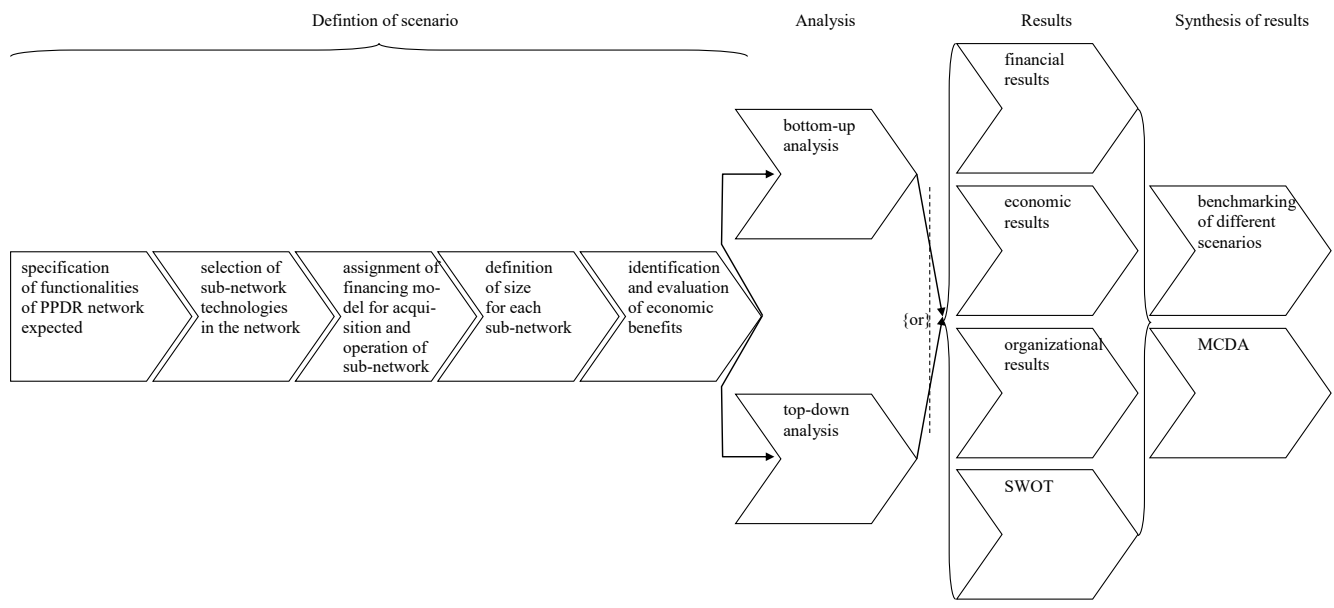

Figure 1. Multi-stage process to analyze scenarios of business models

Source: own figure.

The above results are used to prepare benchmarking that allows to compare scenarios and to do Multi-Criteria Decision Analysis (MCDA). A decision maker can use the advice of a decision support system based on $R$ software framework that delivers some hints using results of MCDA package of $R$. The following functions were implemented: ELECTRE TRI (ELimination Et Choix Traduisant la REalité), UTA (UTilites Additives), UTADIS (UTilites Additives Discriminates), UTASTAR, TOPSIS (Technique for Order of Preference by Similarity to Ideal Solution), and MARE (Multi-Attribute Range Evaluations). They evaluate a scenario using a list of results obtained in the technical, financial, economic, and SWOT analysis. An end-user can select quantities, weights, as well as thresholds for compliance and non-compliance tests. These quantities calculated during the analysis and incorporated into the multi-criteria evaluation of the results are: the number of voice, narrowband, broadband, video, transversal and challenging services, NPV, ENPV, CAPEX, OPEX, TCO, the number of strength, weakness, opportunities and threats, and also frequency band. 


\section{Business models for acquisition and operation of a PPDR system}

Following the trend to use broadband services that become a standard in nowadays fixed and mobile networks, PPDR organizations tend to migrate to broadband radio networks in order to have possibilities for quick and efficient data exchange, including video streaming and database access. Such a technological evolution is expensive because many infrastructure components have to be upgraded or even replaced. That is why, many organizations look for new business models that allow reducing the expenditures. In this case study, the business models proposed by CEPT ECC FM49 Radio Spectrum for PPDR working group (CEPT, 2014) are analyzed. The following options of network acquisition and different sub-models are taken into consideration:

1. Dedicated network infrastructure for PPDR:

1.1. Mobile broadband network planned, built, run, and owned by the authority.

1.2. Mobile broadband service provided through service offering.

1.3. Mobile broadband network planned, built, run, and owned by the PPDR agency, but broadband service meets less tight requirements.

2. Commercial network(s) infrastructure providing broadband services to PPDR users:

2.1. Same mobile broadband services to PPDR as for public customers.

2.2. Mobile broadband services to PPDR with special requirements.

3. Hybrid solutions with partly dedicated and partly commercial network infrastructure:

3.1. Geographical split between dedicated and commercial network infrastructure.

3.2. Mobile Virtual Network Operator (MVNO) model where PPDR users share Radio Access Network (RAN) with the public users.

3.3. MVNO model with partly dedicated/partly shared RAN network.

3.4. Extended MVNO model where PPDR have dedicated core and service nodes and dedicated carriers in the radio transmitters/receivers in the RAN part of the commercial mobile broadband network.

The details about the above sub-models can be found in Gierszal et al. (2014). This case study assumes that a nation-wide mobile network is acquired by a PPDR agency using one of 9 sub-models listed above. The new network will consist of two sub-networks: mature narrowband TETRA one and broadband LTE or WiMAX one. WiMAX technology is applied in sub-models 1.3. It is important to notice that this technology cannot meet all the needs for the services required by PPDR organizations due to limitation in maximum throughput of the radio interface. Moreover, the planned network will replace an analogue legacy system that provides 
only narrowband services like voice and text messages. The analyses were done taking into account the following assumptions:

- discount rate for cash flow: 8\%,

- lifetime of the project: 15 years,

- investment period: 4 years,

- warranty period for the equipment: 2 years,

- yearly increase in a number of terminals: $1 \%$,

- coverage area of the system: $312,000 \mathrm{~km}^{2}$,

- number of handheld terminals: 100,000 TETRA and 1,000 LTE,

- number of other types of terminals: 1,000 TETRA and 10,000 LTE or WiMAX,

- number of national NOCs: 1 ,

- number of regional NOCs: 16 ,

- number of dispatchers centres: 380 ,

- number of mobile switches: 17 ,

- number of interoperability gateways: 3 ,

- number of radiolinks: 2,670,

- length of the backbone network: 20,900 km,

- number of masts: existing $-20 \%$, to be built $-50 \%$, and to be leased $-30 \%$.

The results of a financial analysis are summarized in Table 1 where TCO, NPV, and ENPV values are reported for each of the sub-models. In all sub-models NPV values are negative. It means that none of the sub-models is financially worth doing. On the other hand, PPDR obligations are, in general, loss-making, because they aim at increasing the security and safety of citizens, country, and the economy, and not at maximizing the business incomes. This economic aspect and its contribution to the wealth of the society can be seen, however, if ENPV values are analyzed. They are significantly great. It means that the overall financial-economic result of each sub-model is favourable. The most efficient result of the financial analysis (TCO and NPV) is obtained for sub-model 1.3. On the other hand, sub-model 3.2 is the most favourable in the economic term (ENPV).

In Figure 2, CAPEX and OPEX, as well as yearly TCO per user, and DGC are depicted. In all sub-models, OPEX dominates, but, in general, sub-models 1.1 and 1.3 are based on CAPEX, while sub-models 1.2, 2.1, and 2.2 - on OPEX. The hybrid sub-models (3.1, 3.2, 3.3, and 3.4) consist of a balanced split of expenditures between investment capitals and operational costs. One can notice that CAPEX-oriented models allow reducing total expenditures, because the large number of terminals is acquired by purchasing by a PPDR organization, and not by 
A.

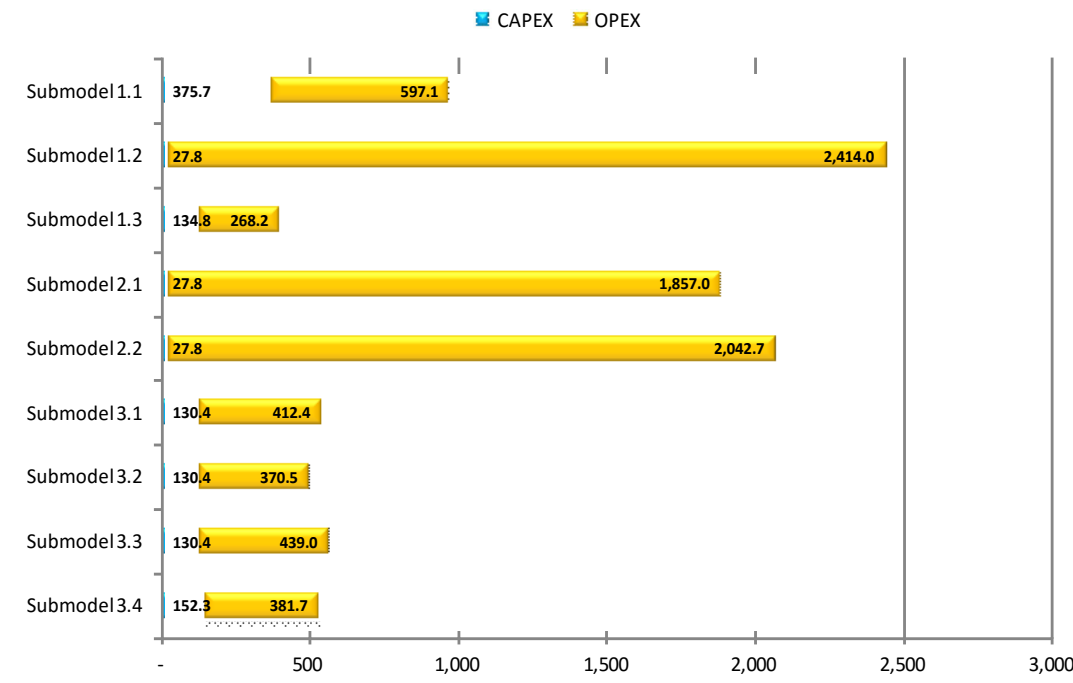

DGC (person-month) [€] $\square$ TCO yearly per 1 user $[€]$

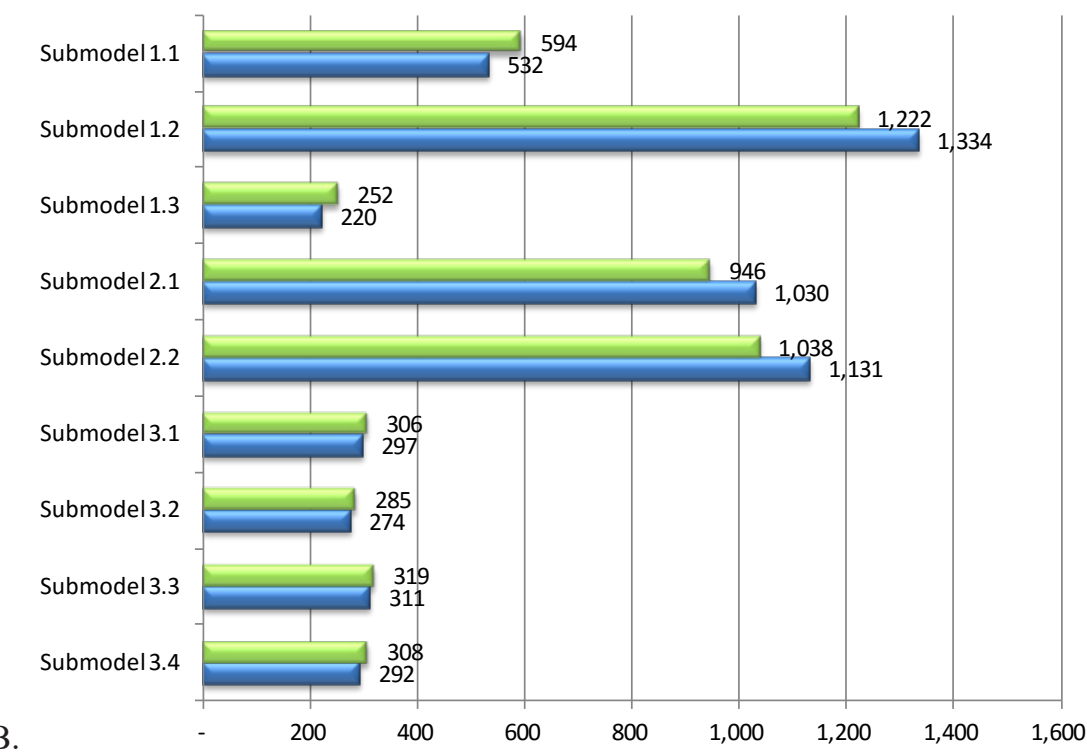

Figure 2. A - CAPEX and OPEX comparison (mln EUR) as well as B - yearly TCO per user and DCG (EUR)

Source: own figures. 
costly leasing from a service provider. In TCO measure, sub-model 1.2 is the most expensive, and sub-model 1.3 is the cheapest. Excluding sub-model 1.3 that does not meet PPDR expectations, sub-model 1.1 (own network) and hybrid ones (sub-models 3.x) are preferable.

Table 1. Results of financial and economic analysis (EUR)

\begin{tabular}{|c|c|c|c|}
\hline Sub-model & TCO (for 15 years) & NPV (last year of the analysis) & ENPV (last year of the analysis) \\
\hline 1.1. & $972,859,588$ & $-627,265,442$ & $783,217,066$ \\
\hline 1.2. & $2,441,820,758$ & $-1,314,319,550$ & $96,162,958$ \\
\hline 1.3. & $403,037,171$ & $-250,919,912$ & $1,068,572,279$ \\
\hline 2.1. & $1,884,828,038$ & $-1,017,116,795$ & $393,365,713$ \\
\hline 2.2. & $2,070,492,278$ & $-1,116,184,380$ & $294,298,128$ \\
\hline 3.1. & $542,769,531$ & $-326,399,227$ & $1,084,083,281$ \\
\hline 3.2. & $500,925,231$ & $-304,070,963$ & $1,106,411,545$ \\
\hline 3.3. & $569,408,031$ & $-340,612,387$ & $1,069,870,121$ \\
\hline 3.4. & $533,968,590$ & $-327,975,582$ & $1,082,506,927$ \\
\hline
\end{tabular}

Source: own results.

The result of the multi-criteria analysis using ELECTRE TRI method classifies submodels in the following hierarchy (from the less favourable one): 1.2, 2.2, 2.1, 1.1, 3.3, 3.4, 3.1, 3.2, and 1.3. In this way, it is possible to obtain a ranking of business models. The hierarchy of sub-models depends on the weights assigned to each criterion.

\section{Efficiency of network acquisition in different countries}

This section contains the comparison of existing or planned networks in: Poland, United Kingdom (UK), Hungary, Finland, and Estonia. For this analysis, we selected networks of different telecommunication technologies (TETRA, CDMA), ownerships (own, leased), and operational models (own, outsourcing). The assumed data are presented in Table 2.

Those networks can be characterized by different operational areas and numbers of users, so it is better to compare them using relative values (e.g. TCO per $1 \mathrm{user}$, TCO per $1 \mathrm{~km}^{2}$, etc.) than absolute amounts (e.g. CAPEX, OPEX, TCO per year). TCO for a 10-year period of the undertaking is shown per one user and per $1 \mathrm{~km}^{2}$ in Figure $3 \mathrm{TCO}$ per $1 \mathrm{~km}^{2}$ is the most favourable for Finland, but, at the same time, TCO per one citizen is the most expensive. On the other hand, TCO per one citizen is quite small in UK, but, simultaneously, TCO per $1 \mathrm{~km}^{2}$ is very large. Thus, depending on the economy and national conditions, investment projects can be assessed differently, and the expert who does such calculations may manipulate the final evaluation of the project. 
Tabele 2. Assumptions for radio networks in each country

\begin{tabular}{|c|c|c|c|c|c|}
\hline & Poland & UK & Hungary & Finland & Estonia \\
\hline $1^{\text {st }}$ technology & CDMA & TETRA & TETRA & $\begin{array}{l}\text { TETRA: } 60 \% \\
\text { coverage }\end{array}$ & TETRA \\
\hline Financing model & leased & leased & leased & own & own \\
\hline Operation model & outsourcing & outsourcing & outsourcing & own & outsourcing \\
\hline $2^{\text {nd }}$ technology & - & - & - & $\begin{array}{l}\text { TETRA2: } 40 \% \\
\text { coverage }\end{array}$ & - \\
\hline Financing model & - & - & - & own & - \\
\hline Operation model & - & - & - & own & - \\
\hline $\begin{array}{l}\text { Number of handheld } \\
\text { terminals }\end{array}$ & 90,000 & 180,000 & 40,000 (together) & $\begin{array}{c}\text { 60,000 (TETRA: } \\
\text { 36,000/TETRA2: } \\
\text { 24,000) }\end{array}$ & 10,000 \\
\hline $\begin{array}{l}\text { Number of other } \\
\text { terminals }\end{array}$ & 10,000 & 18,000 & & $\begin{array}{c}6,000 \\
(3,600 / 2,400)\end{array}$ & 1,000 \\
\hline $\begin{array}{l}\text { Number of base } \\
\text { stations }\end{array}$ & 1,102 & 3,000 & 270 & $\begin{array}{c}1,300 \\
(780 / 520)\end{array}$ & 100 \\
\hline $\begin{array}{l}\text { Investment period } \\
\text { (years) }\end{array}$ & 2 & 2 & 2 & 3 & 3 \\
\hline $\begin{array}{l}\text { Discount for } \\
\text { equipment }\end{array}$ & $0 \%$ & $0 \%$ & $0 \%$ & - & - \\
\hline $\begin{array}{l}\text { One-time fee for } \\
\text { leased terminal } \\
\text { (EUR) }\end{array}$ & 0 & 120.50 & 75 & - & - \\
\hline $\begin{array}{l}\text { Monthly fee for } \\
\text { leased handheld } \\
\text { terminal (EUR) }\end{array}$ & 65 & 82.60 & 74 & - & - \\
\hline $\begin{array}{l}\text { Monthly fee for } \\
\text { leased other terminal } \\
\text { (EUR) }\end{array}$ & 36 & 82.60 & 74 & - & - \\
\hline $\begin{array}{l}\text { Monthly fee for } \\
\text { outsourcing terminal } \\
\text { (EUR) }\end{array}$ & 0 & 0 & 0 & - & - \\
\hline $\begin{array}{l}\text { Fees for training } \\
\text { (EUR) }\end{array}$ & - & $\begin{array}{c}\text { training courses } \\
\text { for dispatchers: } \\
0 \\
\text { training } \\
\text { courses for } \\
\text { administrators: } \\
1,205\end{array}$ & $\begin{array}{c}\text { training courses: } \\
0\end{array}$ & - & - \\
\hline
\end{tabular}

Source: own list of assumptions. 


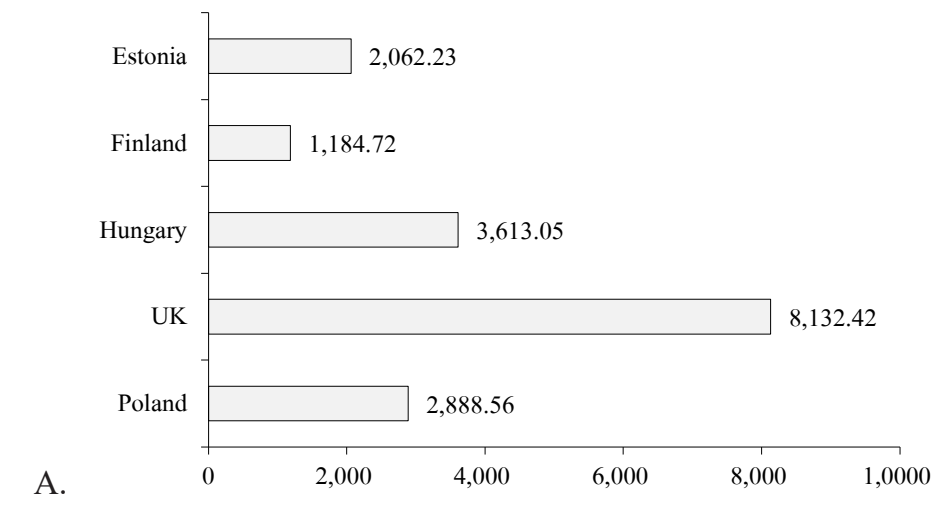

B.

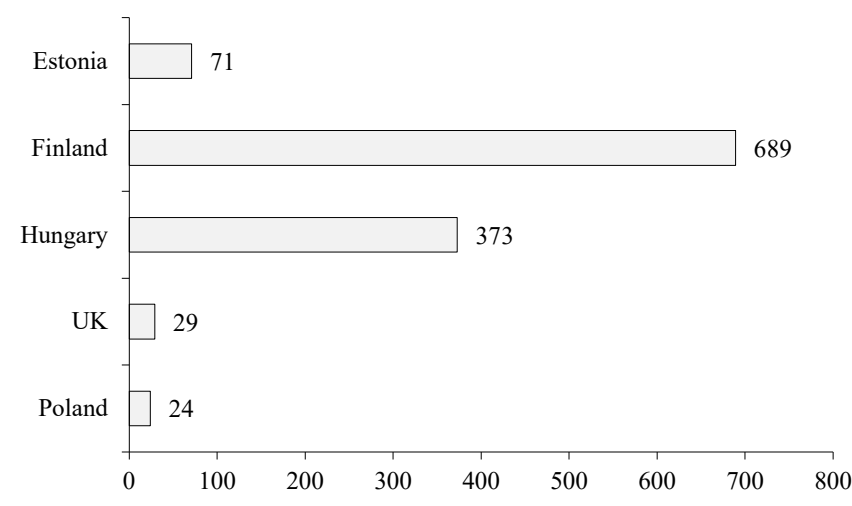

Figure 3. Comparison of yearly TCO per A $-1 \mathrm{~km}^{2}$ and B -1 citizen (EUR) Source: own figures.

\section{Selection of technology for a nation-wide radio dispatching network}

Another case study concerns the acquisition of a nation-wide radio dispatching network for the energy sector. This process can be based on one of the two models:

- own TETRA network built and operated by the investor - CAPEX and OPEX are borne,

- PMR CDMA communication service leased by the investor from a network operator that provides services on the basis of CDMA2000 network - only OPEX is borne.

Investments are summarized in Table 3 where infrastructure items are specified. 
Table 3. Assuptions for investments

\begin{tabular}{|c|c|c|c|}
\hline \multicolumn{2}{|c|}{ Assumptions of access and backhaul networks } & \multicolumn{2}{|c|}{ Assumptions of core network } \\
\hline Number of base stations & 1,102 & Number of national NOCs & 2 \\
\hline $\begin{array}{l}\text { Percentage of existing locations that are not } \\
\text { used in a new network }\end{array}$ & $5 \%$ & Number of regional NOCs & 5 \\
\hline Number of existing locations & 408 & Number of switches & 10 \\
\hline Annual insurance & $0.083 \%$ & Number of dispatching consoles & 100 \\
\hline Number of radiolinks & 496 & Network Management Center & 7 \\
\hline Number of leased locations & 320 & $\begin{array}{l}\text { Number of buildings that require } \\
\text { modernizations for switches }\end{array}$ & 10 \\
\hline Number of new locations to be built & 374 & $\begin{array}{l}\text { Equipment and software for Network } \\
\text { maintenance }\end{array}$ & 7 \\
\hline $\begin{array}{l}\text { Own existing locations that need an } \\
\text { additional room to be built }\end{array}$ & 8 & $\begin{array}{l}\text { Number of analog-digital gateways for } \\
\text { TETRA }\end{array}$ & 7 \\
\hline $\begin{array}{l}\text { Locations where the masts have to be } \\
\text { modernized }\end{array}$ & 142 & $\begin{array}{l}\text { Number of analog-digital gateways for } \\
\text { CDMA }\end{array}$ & 7 \\
\hline $\begin{array}{l}\text { Locations that have to be modernized } \\
\text { during the network development }\end{array}$ & 385 & $\begin{array}{l}\text { Number of digital-digital gateways for } \\
\text { TETRA-CDMA }\end{array}$ & 2 \\
\hline $\begin{array}{l}\text { Locations where the heigh of masts has to } \\
\text { be increased to } 40 \mathrm{~m}\end{array}$ & 20 & & \\
\hline $\begin{array}{l}\text { Locations where the masts have to } \\
\text { be modernized to host two antenna } \\
\text { installations }\end{array}$ & 102 & & \\
\hline $\begin{array}{l}\text { Own existing locations where rooms need } \\
\text { to be modernized }\end{array}$ & 20 & & \\
\hline
\end{tabular}

Source: own list of assumptions.

In both cases, the following economic benefits are gained:

a) automation in the control of a medium-voltage grid, as well as evolution toward the smart grid allow reducing the duration of failures when the power is down and the energy is not provided to the users;

b) due to automation of remote controlling in a medium-voltage network, the number of interventions of the staff in the field can be decreased;

c) the efficiency of operational and maintaining works done by the staff can be increased;

d) using the new communication digital network, the smart grid allows reducing the power demand, and thus a probability of the blackout can be reduced.

In the case of TETRA network, the great CAPEX can be compensated from the smaller OPEX. For CAPEX, the network based on PMR CDMA service is more efficient than TETRA one if the operation is shorter than 11 years. For a longer period, TETRA network becomes more favourable for the investor. The economic effectiveness can be reached after ca. 10 years in both models. The benefit is reached a little quicker in the case of PMR CDMA service, because 
CAPEX is reduced, but due to the great OPEX, the economic effectiveness increases slower as compared to the case of TETRA network. Finally, it leads to the result that after 15 years, greater economic effectiveness can be obtained from TETRA network. The economic effectiveness expressed by ENPV is shown in Figure 4.

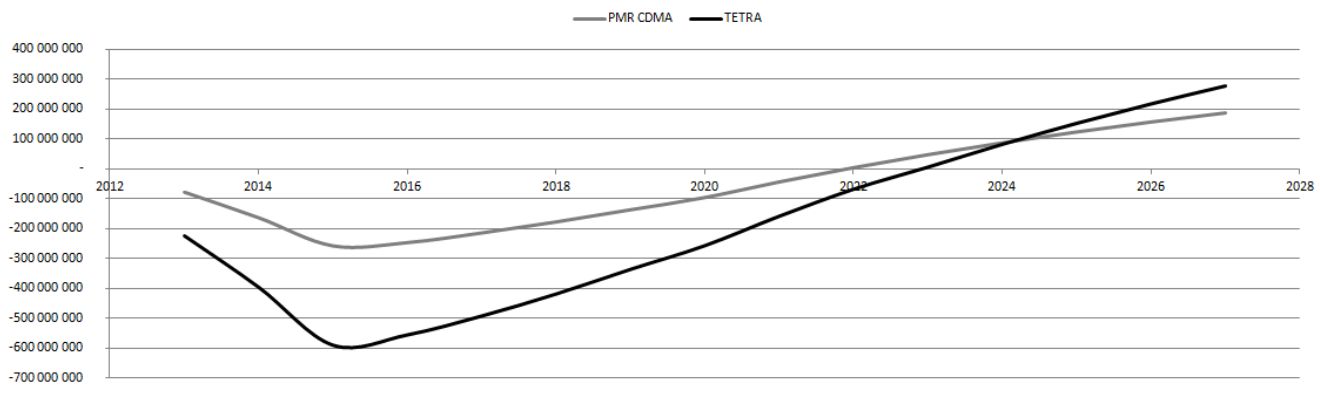

Figure 4. ENPV for both models (PLN)

Source: own figure.

\section{Radio dispatching network for crisis management in a voivodeship}

The tool also allows preparing a breakdown of expenditures into CAPEX and OPEX as well as Budgeted Cost of Work Scheduled (BCWS). The example project based on the DMR (Digital Mobile Radio) standard is divided into three stages:

I. communication for a voivodeship;

II. communication for a county;

III. management system for:

a) the alarm sirens that are already radio-controlled,

b) remaining alarm sirens.

An example of BCWS is shown in Table 4 Radio equipment and software comprise: repeaters (different types including mobile ones), radiolinks, consoles, console servers, equipment and software for personnel involved in maintenance, network management sub-system, backhaul management sub-system, voice recorder, licences for radio-servers, application for messaging, management system for alarm sirens, servers for the control of alarm sirens, software of trunking functionality, and works for the integration of sub-networks. Auxiliary equipment includes satellite links and mobile data transmission (modems). 
Table 4. BCWS for the acquisition of radio dispatching network (PLN)

\begin{tabular}{|l|r|r|r|r|r|r|r|r|r|r|}
\hline \multicolumn{1}{|c|}{ Cost } & Total & 2013 & 2014 & 2015 & 2016 & 2017 & 2018 & 2019 & 2020 & 2021 \\
\hline $\begin{array}{l}\text { Radio } \\
\text { equipment } \\
\& \text { software }\end{array}$ & $3,478,108$ & $1,732,754$ & 826,500 & 743,400 & 0 & 0 & 102,500 & 0 & 0 & 0 \\
\hline Terminals & $11,088,952$ & 220,850 & 220,850 & 227,500 & $2,620,700$ & $2,620,700$ & $1,003,908$ & $1,010,276$ & $1,019,544$ & $1,069,128$ \\
\hline $\begin{array}{l}\text { Con- } \\
\text { structions }\end{array}$ & 367,680 & $94,856.67$ & $94,856.67$ & $95,246.67$ & 28,860 & 28,860 & 5,000 & 5,000 & 5,000 & 5,000 \\
\hline $\begin{array}{l}\text { Design and } \\
\text { implemen- } \\
\text { tation }\end{array}$ & 245,000 & 121,000 & 76,000 & 48,000 & 0 & 0 & 0 & 0 & 0 & 0 \\
\hline $\begin{array}{l}\text { Auxiliary } \\
\text { equipment }\end{array}$ & 90,128 & 54,976 & 19,826 & 15,326 & 0 & 0 & 0 & 0 & 0 & 0 \\
\hline Total & $15,369,868$ & $2,324,437$ & $1,238,033$ & $1,129,473$ & $2,649,560$ & $2,649,560$ & $1,111,408$ & $1,015,276$ & $1,024,544$ & $1,074,128$ \\
\hline
\end{tabular}

Source: own results.

The most costly item is the purchase of mobile terminals. The network elements of core and access layers are also expensive. The results show that it is possible to distribute terminal costs for many years, and focus on the network infrastructure at the beginning of the project in order to acquire a more flexible network to meet requirements related to its capacity, reliability, and availability.

\section{Radio communication network for areas with significant attenuation of radio signal}

The last example concerns a national organization that works in the areas where it is difficult to provide good radio coverage due to high attenuation of the existing types of clutters (e.g. forest). The network designed is based on DMR standard and is addressed to 100,000 mobile users. The operator has to lease a backbone network and build a backhaul one. There is one

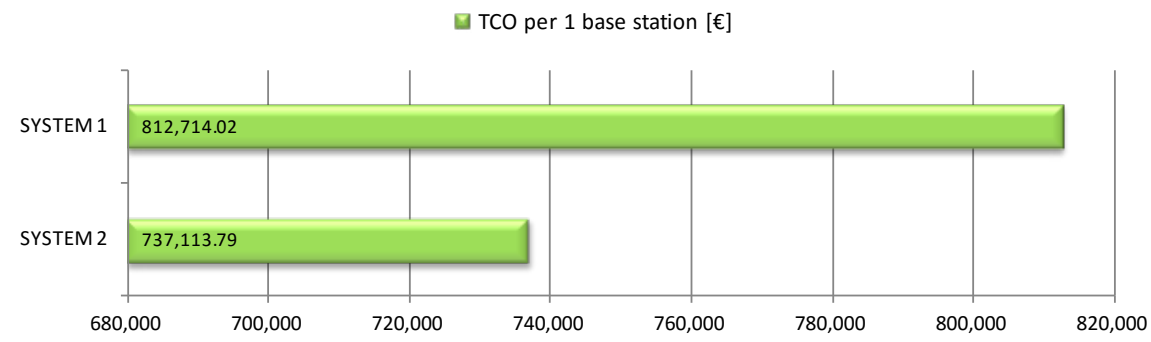

Figure 5. TCO per base station for nominal (System 2) and oversized (System 1) radio propagation plans for 10-year lifetime

Source: own figure. 
national Network Operation Centre (NOC) and 16 regional ones. In this case, it was decided to oversize a number of base stations in order to increase the level of transmit signal, and to ensure better coverage. TCO per base station is shown in Figure 5.

\section{Conclusions}

In this paper, we have presented some aspects of the technical and financial-economic analysis for acquisition of broadband PSC by PPDR organizations. To support the end-users and decision-makers who look for a trade-off between the capitals and PPDR needs, a businessoriented tool has been developed and evaluated. The tool allows for multi-domain analyses of business models taking into account technical, financial, and economic aspects of investment undertakings. Besides different indices to evaluate the efficiency of scenarios, the tool can suggest the best approach(s) for the acquisition of the network composed of up to three subnetworks of different technologies taking into account many factors that affect the efficiency of the resulting PPDR network.

We have also presented a few case studies showing how this tool can be used in the process of selection and optimization of business models. One can easily compare CAPEX, OPEX, efficiency indices, and available functionalities depended on technologies.

The developed tool for technical and financial-economic analyses is a practical solution that can support PPDR decision-makers to select the best strategy for the acquisition of broadband radio communication networks in the future. The tool is flexible because the configuration parameters can be easily changed to fit to new technologies or business models.

\section{Acknowledgment}

This work was supported by European Union in the framework of the FP7-SEC-2012.5.2-1 program - project "Public Protection and Disaster Relief - Transformation Centre - PPDR-TC" (contract no. 313015). A free copy of the software tool is available on a request addressed to: ppdr-tc-tool@itti.com.pl.

The authors would like to thank Witold Hołubowicz and Mateusz Stasik for many discussions about the tool and its functionalities. 


\section{References}

CEPT ECC Radio Spectrum for Public Protection and Disaster Relief (PPDR) working group (2014) FM49(14)008rev1 Network Types part (Draft ECC Report B).

Gierszal, H., Pawlina, K., Tyczka, P., Romanowski, K., Lavaux, D., Katsigiannis, C. (2014). Business models and multi-domain analysis for acquiring broadband PPDR systems. IEEE 10th International Conference on Wireless and Mobile Computing, Networking and Communications (WiMob), 8-10 October 2014, Larnaca, pp. 334-340. DOI 10.1109/ WiMOB.2014.6962191.

Gierszal H., Pawlina K, Urbańska M. (2012). Statistical analysis in research of demand for telecommunication services in mobile networks. Research Papers of Wrockaw University of Economics, 242, pp. 580-589 (in Polish).

Grazia, C.A., Klapez M., Patriciello N., Casoni M., Gierszal H., Tyczka P., Pawlina K., Amditis A., Sdongos E. (2015). Performance evaluation and economic modelling of PPDR communication systems. IEEE 11th International Conference on Wireless and Mobile Computing, Networking and Communications (WiMob), pp. 75-82. DOI 10.1109/ WiMOB.2015.7347943.

Raczka, J. (2003). The cost-effectiveness analysis - a superior alternative to the cost-benefit analysis of environmental infrastructure investments. Fifth European Conference on Evaluation of The Structural Funds "Challenges for Evaluation in an Enlarged Europe", Budapest, 26-27 June. 